\title{
From Bare Metal Powders to Colloidally Stable TCO Dispersions and Transparent Nanoporous Conducting Metal Oxide Thin Films
}

\author{
Engelbert Redel, Chen Huai, Ömer Dag, Srebri Petrov, Paul G. O'Brien, \\ Michael G. Helander, Jacek Mlynarski, and Geoffrey A. Ozin*
}

\begin{abstract}
Transparent conductive oxides (TCOs) are a technologically important class of materials. ${ }^{[1]}$ Herein we describe a facile, universal, and green 'one-pot' approach to produce stable dispersions comprising TCO nanoparticles (NPs) such as $\mathrm{SnO}_{2}, \mathrm{In}_{2} \mathrm{O}_{3}$, ATO $\left(\equiv \mathrm{SnO}_{2}: \mathrm{Sb}\right)$, ITO $\left(\equiv \mathrm{In}_{2} \mathrm{O}_{3}: \mathrm{Sn}\right)$, and ZTO $\left(\equiv \mathrm{SnO}_{2}: \mathrm{Zn}\right)$. The synthesis begins by etching the bare metal powder precursors ( $\mathrm{Sn}, \mathrm{In}, \mathrm{Sb}$, and $\mathrm{Zn}$ ) with $\mathrm{HCl}$ and is completed by adding aqueous hydrogen peroxide below room temperature. No complex work-up or time-consuming purification is required, only simple filtration. Moreover, this approach avoids organic surfactants, capping ligands and/ or organic solvents, metal halides like $\mathrm{SnCl}_{4}$ or $\mathrm{SbCl}_{3}$, coordination compounds and sol-gel precursors like $\mathrm{Sn}(\mathrm{O} t \mathrm{Bu})_{4}$, which are commonly used in all reported syntheses of TCOs NPs and which often contaminate and therefore complicate their subsequent utilization and purification. ${ }^{[2,3]}$ It is noteworthy that TCO nanoparticles have been synthesized in different reaction media including ionic liquids, ${ }^{[4]}$ polyols, ${ }^{[5]}$ and water. ${ }^{[6]}$ The herein reported TCO NPs possess diameters of 3-6 nm, are colloidally stable, can be produced on a multigram scale and are well-suited for spin-coating nanoporous, transparent, and conductive TCO thin films ${ }^{[7]}$ (see Scheme 1) with potential utility in lithium ion batteries, solar and photoelectrochemical cells, electrochromics and sensors, flat-panel displays, transparent thin-film transistors, optoelectronic devices, and photonic crystal architectures. ${ }^{[8-12]}$ Additionally,
\end{abstract}

Dr. E. Redel, C. Huai, Dr. S. Petrov, Dr. P. G. O’Brien

J. Mlynarski, Prof. G. A. Ozin

Lash Miller Chemistry Department

University of Toronto

Centre for Inorganic and Polymeric Nanomaterials

80 St. George Street, Toronto, $\mathrm{M}_{5} \mathrm{~S}_{3} \mathrm{H} 6$, Ontario, Canada

E-mail: gozin@chem.utoronto.ca

Prof. Ö. Dag

Department of Chemistry

Bilkent University

0680o, Ankara, Turkey

M. G. Helander

Department of Materials Science \& Engineering

University of Toronto

184 College Street, Toronto, Ontario, $\mathrm{M}_{5} \mathrm{~S}_{3}$ E4, Canada

DOI: $10.1002 /$ smll.201200864 such TCO dispersions can potentially be ink-jet printed ${ }^{[4,13]}$ or electrospun into TCO nanofibers. ${ }^{[14]}$

The synthesis begins with microscale metal powders exemplified by $\mathrm{Sn}, \mathrm{Zn}, \mathrm{Sb}$, and In (purity 99.5 to $99.95 \%$ ) which are treated first with $\mathrm{HCl}$ (per analysis (p.a.) $37 \mathrm{wt} \%$ ) to dissolve the native metal oxide shell, followed by a very slow and dropwise addition of aqueous $/ \mathrm{H}_{2} \mathrm{O}_{2}$ (p.a. $30 \mathrm{wt} \%$ ) yielding in the complete oxidative dissolution of the etched metal powders and the formation of colloidally stable TCO NP dispersions (see Figure 1a-c).

Due to the highly exothermic nature of our reaction, the synthetic procedure is limited to the preparation of several grams of TCO dispersions on the lab-scale; industrial scalability on a multi-kilogram or multi-ton approach will be not possible with the approach described here. This one-pot TCO synthesis is envisioned as a controlled oxidative dissolution of micrometer-scale metal powder precursors to create metal oxide embryonic seeds which accrete metal oxide solution phase species and grow to form the product metal oxide nanoparticles. ${ }^{[3,19,25]}$

A detailed study of the synthesis is given for $\operatorname{In}_{2} \mathrm{O}_{3}$ and its controlled Sn doping levels (e.g., $\approx 5,10,15$ and $20 \mathrm{wt} \%$ ) of ITO $\left(\equiv \mathrm{In}_{2} \mathrm{O}_{3}: \mathrm{Sn}\right)$. Additionally, and as a proof-of-concept for this method, the formation of $\mathrm{SnO}_{2}$ and ATO $\left(\equiv \mathrm{SnO}_{2}: \mathrm{Sb}\right)$ and ZTO $\left(\equiv \mathrm{SnO}_{2}: \mathrm{Zn}\right)$ are shown (for details see the Supporting Information (SI)). The $\mathrm{Sn}$ and $\mathrm{Sb}$ doping levels in ITO $\left(\equiv \mathrm{In}_{2} \mathrm{O}_{3}: \mathrm{Sn}\right)$ and ATO $\left(\equiv \mathrm{SnO}_{2}: \mathrm{Sb}\right)$ were estimated from powder X-ray diffraction (PXRD) Rietveld analysis with comparisons to published data on lattice parameters (for details see Table S1 and S2 in the SI). ${ }^{[15-17]}$ The increase of the Sn concentration in $\mathrm{In}_{2} \mathrm{O}_{3}$ was confirmed by X-ray photoelectron spectroscopy (XPS) and through conductivity measurements at different doping levels (see SI Figures S26-S29 and Table S6). Furthermore, XPS analysis showed that $\mathrm{HCl}(37 \mathrm{wt} \%)$ is crucial for the complete dissolution of the native metal oxide shell of the employed bare metal precursor (see Figure S27 in the SI). After the complete dissolution of the native metal oxide layer, the respective metal powder(s) forms compact metal agglomerates (see the Experimental Section in the SI). Oxidative dissolution of the metal agglomerate occurs only if the etching process with $\mathrm{HCl}$ was applied beforehand (see also Figure S28, SI). The aqueous TCO syntheses are carried at a low temperature using an ice bath with vigorous stirring 


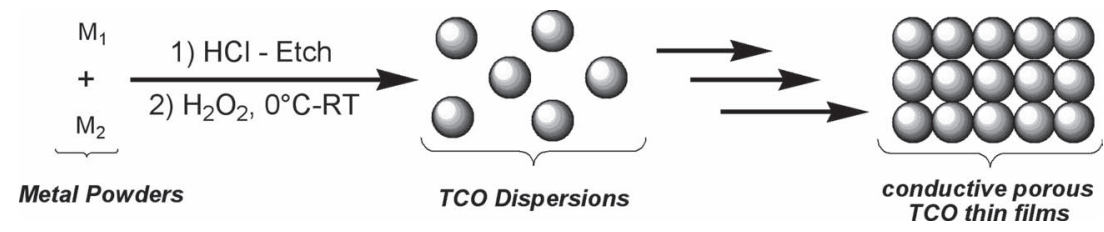

Scheme 1. Transformation of bare metal powder precursors with $M=S n$, In, Sb and $\mathrm{Zn}$ to colloidally stable TCO dispersions and nanoporous TCO thin films.

until dissolution of the used metal precursors is complete, achieving essentially total conversion ( $100 \%$ yield) of microscale metal particles to stable $\mathrm{SnO}_{2}, \mathrm{In}_{2} \mathrm{O}_{3}, \mathrm{ATO}\left(\equiv \mathrm{SnO}_{2}: \mathrm{Sb}\right)$, ITO $\left(\equiv \mathrm{In}_{2} \mathrm{O}_{3}: \mathrm{Sn}\right)$, and ZTO $\left(\equiv \mathrm{SnO}_{2}: \mathrm{Zn}\right)$ NP dispersions (see

Table 1).

Under very acidic conditions $(\mathrm{pH} \approx-1)$, the formation of metal halides is unfavorable due to the high oxidation potential of the $\mathrm{H}_{2} \mathrm{O}_{2} / \mathrm{H}_{2} \mathrm{O}$ redox couple $\left(\mathrm{E}^{0}=1.763 \mathrm{~V}\right)$. ${ }^{[18]}$ It is important to note that crystalline TCO NP dispersions are obtained under conditions between 0 and $25^{\circ} \mathrm{C}$ by simple stirring (see Figures S3-S7 in the SI). Further washing, extraction, or separation and purification steps are not required. Mostly high temperatures- $\approx 200-300{ }^{\circ} \mathrm{C}$ in solvothermal reactions ${ }^{[19]}$ - are required to form crystalline $\mathrm{SnO}_{2}, \mathrm{In}_{2} \mathrm{O}_{3}$, ITO $\left(\equiv \mathrm{In}_{2} \mathrm{O}_{3}: \mathrm{Sn}\right)$ and ATO $\left(\equiv \mathrm{SnO}_{2}: \mathrm{Sb}\right)$ nanoparticles, which also have to be further purified. The straightforward nature of this procedure simplifies NP characterization to form TCO nanoporous thin films for use in gas sensing, ${ }^{[20]}$ photocatalysis, ${ }^{[21]}$ and optoelectronic devices. ${ }^{[22]}$

PXRD confirmed the phase purity of the synthesised $\mathrm{SnO}_{2}$ and $\mathrm{In}_{2} \mathrm{O}_{3}$ as well as the doped ITO, ATO, and ZTO dispersions, where no extraneous peaks could be detected (see SI, Figures S1,S2). Profile fitting procedures (Pawley decomposition and Rietveld refinement) were used for lattice parameter refinement of the pure and doped TCOs. It was found that $\mathrm{Sb}$-doping in $\mathrm{SnO}_{2}$ enlarges the lattice, while Sndoping in $\mathrm{In}_{2} \mathrm{O}_{3}$ does not follow Vegard's Law at the highest levels of Sn doping ( $>10 \mathrm{wt} \%$; for details see SI, Tables S1 and S2). This behavior is in full agreement with published data for $\mathrm{Sn}_{\mathrm{x}} \mathrm{In}_{2-\mathrm{x}} \mathrm{O}_{3}$ composition tuning. ${ }^{[15-17]}$

TCO NP sizes of dried dispersions were obtained from PXRD measurements via full-profile Rietveld refinement, ${ }^{[23]}$
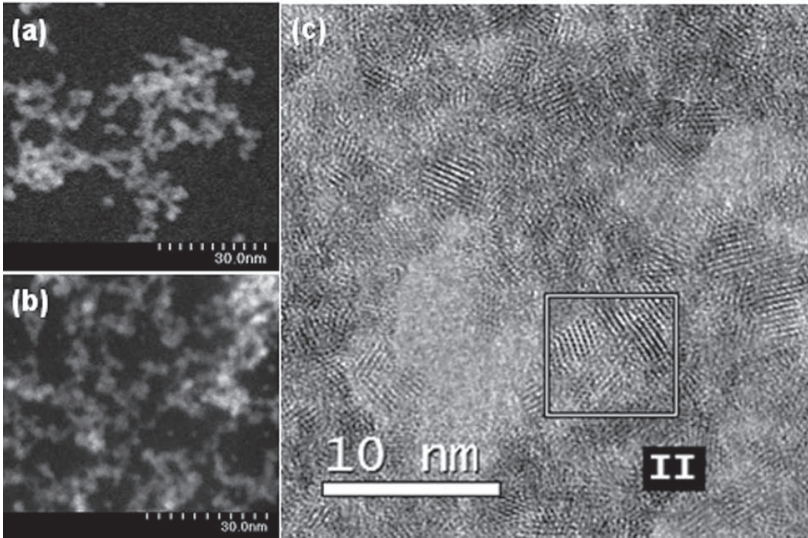

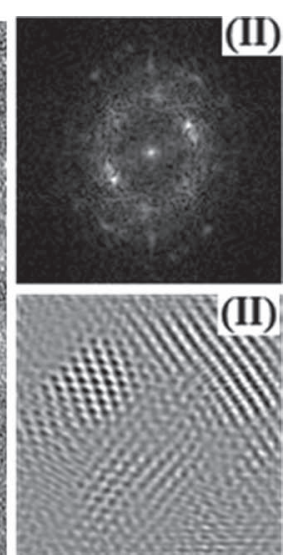

Figure 1. a) STEM image of $\mathrm{In}_{2} \mathrm{O}_{3} \mathrm{NPs}$; b) STEM image of $\mathrm{ZTO}$ ( $\equiv \mathrm{SnO}_{2}: \mathrm{Zn}$ ) NPs; c) HR-TEM image of crystalline $\mathrm{SnO}_{2}$ NPs with selected area, marked II, fast Fourier transform (FFT) and inverse FFT analyses of the image. scanning transmission electron microscopy (STEM), and high-resolution transmission electron microscopy (HR-TEM) techniques, as well as dynamic light scattering (DLS), finding good agreement among these methods, as shown in Table 1 . The HR-TEM and STEM images of $\mathrm{In}_{2} \mathrm{O}_{3}$, ZTO, and $\mathrm{SnO}_{2}$ dispersions are provided in Figure $1 \mathrm{a}-\mathrm{c}$, demonstrating the spherical morphology of crystalline TCO NPs. The observed lattice fringes in the TEM image of $\mathrm{SnO}_{2}$ NPs and further analysis by the fast Fourier transform (FFT) and its inverse FFT of a selected area, marked II, in the TEM image show crystalline domains of the NPs to be consistent with the lattice parameters obtained from the PXRD results (Figure 1c). The colloidal stability of the NPs most likely originates from the presence of electrical double-layer repulsive forces between charged NPs as described by DLVO theory ${ }^{[24,25]}$ while surface charges can be traced to the ionization of surface groups or adsorption of charged species present in the reaction medium (see Scheme 2 and Figure S8 in the SI). From zeta potential measurements, the TCO NPs are found to be positively charged (e.g., $\zeta=41.7 \pm 1 \mathrm{mV}$ for $\mathrm{SnO}_{2}, 26.1 \pm 1.7 \mathrm{mV}$ for ATO $\left(\equiv \mathrm{SnO}_{2}: \mathrm{Sb}\right)$ and $23.5 \pm 1.4 \mathrm{mV}$ for ZTO) under acidic conditions $($ at $\mathrm{pH} \approx 1.3-1.7)$ and diluted $(1: 30),{ }^{[24,25]}$ which is consistent with a protonated surface oxide and/or hydroxide groups (see SI, Table S5). These stabilizing surface species include hydroxonium groups $\left(\mathrm{H}_{3} \mathrm{O}^{+}\right)$, water $\left(-\mathrm{OH}_{2}\right)$, protonated oxygens $\left(-\mathrm{OH}^{+}-\right)$, as well as protonated superoxo/ peroxo groups $\left(-\mathrm{O}-\mathrm{OH}_{2}^{+}\right)$and chloride $\left(\mathrm{Cl}^{-}\right)$all envisioned to be present within the inner Stern Layer and diffuse outer counteranion layer. ${ }^{[26,27]}$ The Raman spectra of the assynthesized and oven-dried dispersions display intense peaks due to surface species that can be mostly eliminated upon calcination. The spectra of the calcined TCO NPs and ATO NPs are similar to bulk counterparts of TCOs (see SI, Figures S19-S23 and Table S4). The colloidal stability most likely results from the presence of chloride counteranions $\left(\mathrm{Cl}^{-}\right)$, evidence for which has been found in dried samples through EDX elemental mapping, as well as from XPS measurements and $\mathrm{M}-\mathrm{Cl}$ stretching and deformation modes in the Raman spectra; for details see SI (Figures S8, S20-23 and S28).

UV-vis-NIR absorption spectra and SEM images of TCO NP films that are spin-coated and then annealed at $450{ }^{\circ} \mathrm{C}$ for 15-20 $\mathrm{min}$ in air, on quartz and/or silicon substrates collectively show the optical quality, structural integrity, and porosity of the films (see SI, Figures S9-S18). The UVvis-NIR spectra of different metal oxide thin films (shown in the SI, Figures S14S18) display characteristic absorption edges that are slightly blue-shifted from their respective bulk metal oxides. The observed blue-shifts are attributed to the nanoscale size of the NP dispersions seen in DLS, STEM, and HR-TEM measurements (further details of the UV-vis-NIR 
Table 1. Characterization of the Size of TCO NPs by STEM, HR-TEM, and DLS.

\begin{tabular}{lcccc}
\hline Metal $^{\text {a }}$ & TCOs & $\begin{array}{c}\text { STEM } \\
{[\mathrm{nm}]^{\mathrm{b})}}\end{array}$ & $\begin{array}{c}\text { HR-TEM } \\
{[\mathrm{nm}]^{\mathrm{c})}}\end{array}$ & $\begin{array}{c}\text { DLS } \\
\left.[\mathrm{nm}]^{\mathrm{c}}\right)\end{array}$ \\
\hline $\mathrm{Sn}$ & $\mathrm{SnO}_{2}$ & $3-6$ & $3.7 \pm 0.4$ & $7.7 \pm 1.6$ \\
In & $\mathrm{In}_{2} \mathrm{O}_{3}$ & $2-6$ & $3.1 \pm 0.3$ & $6.3 \pm 1.3$ \\
$\mathrm{Sn}+\mathrm{Sb}$ & ATO & $6-14$ & $7.8 \pm 1.8$ & $17.5 \pm 2.1$ \\
$\mathrm{In}+\mathrm{Sn}$ & ITO & $2-5$ & $3.2 \pm 0.3$ & $6.5 \pm 1.4$ \\
$\mathrm{Zn}+\mathrm{Sn}$ & ZTO & $3-6$ & $3.5 \pm 0.3$ & $7.5 \pm 1.5$
\end{tabular}

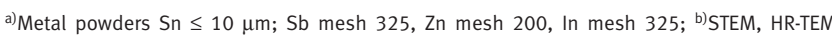
$300 \mathrm{kV}$; ${ }^{\mathrm{c})}$ Nano-ZS DLS at $\lambda=633 \mathrm{~nm}$.

data can be found in the SI, Table S3). Some TCO NP films were also prepared on resistive glass (Corning 1737) in order to measure their sheet resistance using a four point probe station (Four Dimensions, inc. Model 101C). The sheet resistance for films prepared from $\mathrm{SnO}_{2}, \mathrm{In}_{2} \mathrm{O}_{3}$, ATO and ITO NPs annealed at either $450{ }^{\circ} \mathrm{C}$ or $650{ }^{\circ} \mathrm{C}$ for $15-20 \mathrm{~min}$ are shown in Figure 2a. The sheet resistance of the TCO NP films after annealing in air at $650{ }^{\circ} \mathrm{C}$ range from as high as $8.8 \times 10^{7} \Omega / \square$ for the $\mathrm{SnO}_{2} \mathrm{NP}$ film to as low as $4.8 \times 10^{5} \Omega / \square$ for the ITO NP film. Higher annealing temperatures lead to a higher densification and less porosity and grain boundary effects between the adjutant/sintered TCO nanoparticles, therefore resulting in a higher mobility and percolation of electrons throughout the films. We also measured the sheet resistance of the series of films prepared from $\mathrm{In}_{2} \mathrm{O}_{3}$ with controlled $\mathrm{Sn}$ doping levels (e.g., $\approx 5,10,15$, and $20 \mathrm{wt} \%$ ) and the results are shown in Figure 2b. A minimum sheet resistance of $1.9 \times$ $10^{5} \Omega / \square$ was measured for the sample doped with $10 \mathrm{wt} \% \mathrm{Sn}$. This corresponds to a resistivity of $\sim 0.02 \Omega \mathrm{cm}$ which is consistent with values reported previously in the literature. ${ }^{[28]}$ The resistivity of all samples presented in Figure $2 \mathrm{a}, \mathrm{b}$ are listed in SI, Tables S5 and S6.

In conclusion, we have presented a simple, green, robust, widely applicable and cost-effective 'one-pot' multi-gram synthesis to aqueous dispersions of colloidally stable 3-6 nm TCO NPs, using bare metal powder precursors. Their utilization for making TCO high surface area nanoporous films has also been demonstrated, which provides opportunities for their usage in a wide range of processes and devices.

\section{Experimental Section}

Sn, In, Sb, Zn metal powders ( $\leq 10 \mu \mathrm{m}$, mesh 200 and mesh 325, purity $99.9-99.9995 \%$ metal basis), $\mathrm{H}_{2} \mathrm{O}_{2}$ (30\% p.a.) were obtained from Sigma-Aldrich, Alfa Aesar and Caledon Laboratory Chemicals, respectively. Silicon wafers (University Wafer, Lot: 1-800-2168346) were obtained from Wafer World.

$\mathrm{SnO}_{2}, \quad \mathrm{In}_{2} \mathrm{O}_{3}, \quad$ ITO $\quad\left(\equiv \mathrm{In}_{2} \mathrm{O}_{3}: \mathrm{Sn}\right), \quad$ ATO $\left(\equiv \mathrm{SnO}_{2}: \mathrm{Sb}\right)$ and $\mathrm{ZTO}\left(\equiv \mathrm{SnO}_{2}: \mathrm{Zn}\right)$ were synthesized by dissolution of $1-3 \mathrm{~g}$ of the elemental metal powder of $\mathrm{Sn}$, In, Sb or Zn (ASP

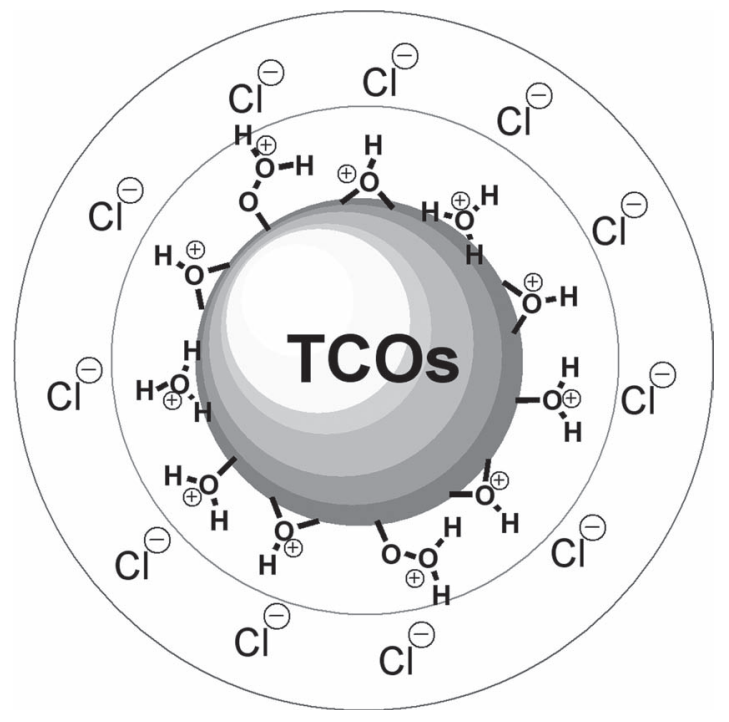

Scheme 2. Illustration of the double-layer surface charge stabilization responsible for the colloidal stability of TCO NPs with a protonated inner Stern Layer and a diffuse outer chloride counteranion layer. ${ }^{[26,27]}$

$\leq 10 \mu \mathrm{m}$, mesh 200 and 325), dispersed in $5 \mathrm{~mL}$ of deionised $\mathrm{H}_{2} \mathrm{O}$ $(0.056 \mu \mathrm{S} / \mathrm{cm})$, followed by the addition of $8 \mathrm{~mL} \mathrm{HCl}$ (37 wt\%) at $0{ }^{\circ} \mathrm{C}$ and, after $\approx 20$ to (max.) $30 \mathrm{~min}$, the slow and dropwise addition of $10-25 \mathrm{~mL} \mathrm{H} \mathrm{O}_{2}$ (30\% p.a.) under nitrogen while cooling the reaction mixture in an ice bath due to the exothermic nature of the dissolution/oxidation process, followed by further stirring of the mixture for $12-18 \mathrm{~h}$ under air/nitrogen. Addition of $\mathrm{HCl}$ causes the complete dissolution of the native metal oxide layer of the respective metal powder(s) and causes the metal powder(s) to agglomerate into a compact metal piece.This synthetic procedure, for each of the metal oxide dispersions from their respective bare metal precursors, has been reproduced at least 3-5 times.

CAUTION: Very exothermic reaction! Addition of the $\mathrm{HCl}$ and $\mathrm{H}_{2} \mathrm{O}_{2}$ has to be done slowly and dropwise, with continuous ice-bath cooling during the addition and reaction/dissolution processes, in a well ventilated hood. Protective glasses, gloves and a lab coat must be worn at all times during this synthetic procedure, and it is recommended that the procedure should be carried out only by a well-trained scientist! The 250 or $500 \mathrm{~mL}$ 2-neck round-bottom
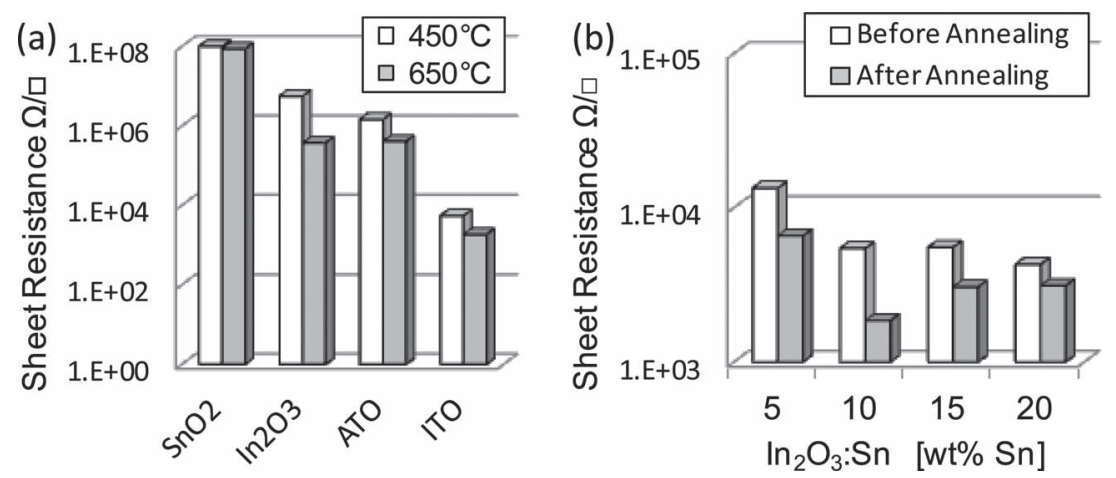

Figure 2. a) Sheet resistance measurements for various TCO NP films annealed at either 450 or $650^{\circ} \mathrm{C}$. b) Sheet resistance of $\ln _{2} \mathrm{O}_{3} \mathrm{NP}$ films doped with various concentrations of $\mathrm{Sn}$ before and after being annealed at $650^{\circ} \mathrm{C}$. 
flask reaction vessel should be never closed too tightly. Final stirring of the reaction mixture at room temperature overnight leads, for example, to a light-yellow to yellow $\mathrm{In}_{2} \mathrm{O}_{3}$ dispersion, a transparent-milky $\mathrm{SnO}_{2}$ dispersion, or a blue-gray ATO $\left(\equiv \mathrm{SnO}_{2}: \mathrm{Sb}\right)$ dispersion. The dispersions were stored in plastic bottles at $4{ }^{\circ} \mathrm{C}$ and the bottle caps additionally had holes in them. Dopants were introduced by weighing metal powders according to their molar ratios to obtain the desired TCO NP products.

\section{Supporting Information}

Supporting Information is available from the Wiley Online Library or from the author.

\section{Acknowledgements}

G.A.O. is Government of Canada Research Chair in Materials Chemistry and Nanochemistry. He thanks NSERC for strong and sustained support of his research. E.R. thanks the Alexander von Humboldt (AvH) Foundation for a Feodor Lynen Postdoctoral Fellowship. Ö.D. thanks Bilkent University and the Turkish Academy of Science for financial support.

[1] D. S. Ginley, J. D. Perkins, in Handbook of Transparent Conductors (Eds: D. S. Ginley, H. Hosono, D. C. Paine), Springer Science + Business Media, New York, USA 2010; pp.1-25.

[2] G. R. Patzke, Y. Zhou, R. Kontic, F. Conrad, Angew. Chem. Int. Ed. 2011, 50, 826-859.

[3] M. Niederberger, N. Pinna, Metal Oxide Nanoparticles in Organic Solvents; Springer-Verlag, London 2009; pp.53-95.

[4] G. Bühler, D. Thölmann, C. Feldmann, Adv. Mater. 2007, 19, 2224-2227.

[5] E. Hammarberg, A. Prodi-Schwab, C. Feldmann, Thin Solid Films 2008, 516, 7437-7442.

[6] C. Goebbert, R. Nonninger, M. A. Aegerter, H. Schmidt, Thin Solid Films 1999, 351, 79-84.

[7] a) Y.-S. Cho, G.-R. Yi, J.-J. Hong, S. H. Jang, S.-M. Yang, Thin Solid Films 2006, 515, 1864-1871; b) R. A. Gilstrap Jr., C. J. Capozzi, C. G. Carson, R. A. Gerhardt, C. J. Summers, Adv. Mater. 2008, 20, 4163-4166.
[8] J. A. Rodriguez, M. Fernandez-Garcia, Synthesis, Properties, and Applications of Oxide Nanomaterials, WILEY InterScience, New York 2007, pp.79-119.

[9] M. Niederberger, M. Antonietti, in Nanomaterials Chemistry: Recent Developments and New Directions (Eds: N. R. C. Rao, A. Mueller, A. K. Cheetham), Wiley-VCH, Weinheim 2007, pp.119-139.

[10] D. P. Puzzo, L. D. Bonifacio, J. Oreopoulos, C. M. Yip, I. Manners, G. A. Ozin, J. Mater Chem. 2009, 19, 3500-3506.

[11] J. L. G. Fierro, Metal Oxides Chemistry and Applications, CRC Press, Taylor \& Francis Group, USA 2006, pp.413-765.

[12] V. E. Henrich, P. A. Cox, The Surface Science of Metal Oxides, Cambridge University Press, New York 1994, pp.77-246.

[13] H.-Y. Lai, T. H. Chen, C. H. Chen, Mater. Lett. 2011, 65, 3336-3339.

[14] R. Ostermann, R. Zieba, M. Rudolph, D. Schlettwein, B. M. Smarsly, Chem. Commun. 2011, 47, 12119-12121.

[15] J. Ba, D. F. Rohlfing, A. Feldhoff, T. Brezesinski, I. Djerdj, M. Wark, M. Niederberger, Chem. Mater. 2006, 18, 2848-2854.

[16] N. Nadaud, N. Lequeux, M. Nanot, J. Jove, T. Roisnel, J. Solid State Chem. 1998, 135, 140-148.

[17] J. Zhang, L. Gao, Inorg. Chem. Commun. 2004, 7, 91-93.

[18] N. Wiberg, Lehrbuch der Anorganischen Chemie, Walter de Gruyter, Berlin 1995, pp.1843-1846.

[19] a) N. Pinna, G. Neri, M. Antonietti, M. Niederberger, Angew. Chem. Int. Ed. 2004, 43, 4345-4349; b) J. Ba, A. Feldhoff, D. F. Rohlfing, M. Wark, M. Antonietti, M. Niederberger, Small 2007, 3, 310-317.

[20] L. D. Bonifacio, D. P. Puzzo, S. Breslav, B. M. Willey, A. McGeer, G. A. Ozin, Adv. Mater. 2010, 22, 1351-1354.

[21] U. Heiz, U. Landman, Nanocatalysis, Springer-Verlag, Berlin 2008 pp. $245-374$

[22] J. Piprek, Semiconductor Optoelectronic Devices, Academic Press, London UK 2003, pp.149-212.

[23] Topas, v. 2.1, General Profile and Structure Analysis Software for Powder Diffraction Data, User's Manual, APS Bruker, Karlsruhe, Germany 2003.

[24] E. J. W. Verway, J. Th. G. Overbeek, Theory of the Stability of Lyophobic Colloids, Elsevier, Amsterdam 1948, pp.22-65.

[25] a) G. Garnweiler, M. Niederberger, J. Mater Chem. 2008, 18, 1171-1182; b) M. Niederberger, G. Garnweiler, Chem. Eur. J. 2006, 12, 7282-7302.

[26] E. Redel, P. Mirtchev, C. Huai, S. Petrov, G. A. Ozin, ACS Nano 2011, 5, 2861-2869.

[27] E. Redel, S. Petrov, Ö. Dag, J. Moir, C. Huai, P. Mirtchev, G. A. Ozin, Small 2012, 8, 68-72.

[28] D. Burgard, C. Goebbert, R. Nass, J. Sol-Gel Sci. Technol. 1998, 13, 789-792.

[29] I. Hamberg, C. G. Granqvist, J. Appl. Phys. 1986, 60, R123.

Received: April 22, 2012

Published online: October 4, 2012 